\title{
Foreword: South African Journal of Geomatics Special Edition
}

This special edition of the South African Journal of Geomatics is the result of efforts by scholars and practitioners in South Africa in the field of geomatics. All papers were blind refereed by two referees, whose reports were then considered prior to selection for publication. The outcome of this work is a collection of eleven articles that demonstrate innovation in the four geomatics themes selected for this Special Edition, namely remote sensing, image analysis, mine surveying and GIS. This would not be possible without the excellent papers contributed by authors. We thank all the authors for their contributions and their participation in this Special Edition of the South African Journal of Geomatics.

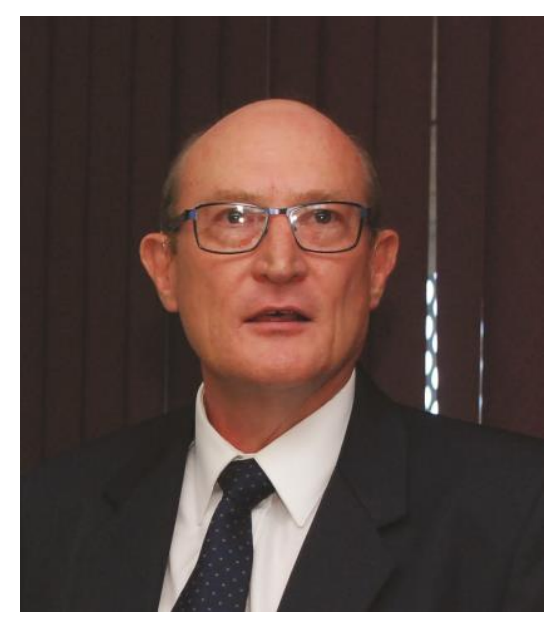

Prof. Fred Cawood

The remote sensing theme consisted of two papers. Cilence Munghemezulu, Ludwig Combrinck, Joel Botai and Zinhle Mashaba mapped multipath as part of the site investigation for the installation of a timing antenna for lunar laser ranging applications at the Hartebeesthoek Radio Astronomy Observatory (HartRAO). They concluded that the site is suitable for such installation and that a mast of $15-20^{\circ}$ elevation angle should be applied in order to minimise multipath errors at lower elevations. Marinus Axel Boon, Richard Greenfield and Solomon Tesfamichael presented the results of a study that aimed to investigate the use of UAV photogrammetry as a tool for mapping wetlands. A multi-rotor UAV and a digital camera on a motion compensated gimbal mount were utilised for the survey. The results provided for rapid and accurate mapping of wetlands that can be used for wetland studies.

The second theme of image analysis contributes to knowledge of spatio-temporal processes. Zakariyyaa Oumar assessed the potential of the SPOT 6 multispectral sensor and two broadband vegetation indices (NDVI and SR) for detecting and mapping Lantana camara on community grazing land in KwaZulu-Natal, South Africa. He indicated the potential of satellite remote sensing in weed detection and mapping using readily available multispectral data to assist poorer communities in grazing management. In a similar 
approach, Bambo Dubula, Solomon Gebremariam Tefsamichael and Isaac Tebogo Rampedi studied the usefulness of remote sensing to discriminate Seriphium plumosum from grass using field spectrometer data. They investigated the possibility of extending field-based information into airborne and spaceborne remote sensing techniques. Lazarus Chapungu and Luxon Nhamo assessed the effects of climate change on vegetative species diversity, exploring the usefulness of the Normalised Difference Water Index (NDWI) in predicting spatio-temporal diversity variations. They concluded that there is a significant correlation between species diversity and the two climatic variables. They also revealed a decrease, though not statistically significant, in the rainfall received within the catchment over the period. In another such study Zinhle Mashaba, George Chirima, Joel Botai, Ludwig Combrinck and Cilence Munghemezulu explored the application of Land Surface Temperature (LST)-vegetation index relationships for winter wheat in order to determine indices that are sensitive to changes in the wheat health status. The indices were derived from Landsat 8 scenes over the wheat growing area in the Bloemfontein district. They demonstrated that LST exhibited an opposing trend with the vegetation abundance indices and an analogous trend with the moisture indices. They also proved the Normalised Difference Vegetation Index (NDVI) to be a better index for winter wheat abundance as compared to the Green Normalised Difference Vegetation Index (GNDVI).

The third theme focused on mine surveying. Hendrik Grobler provided a short history of the development of three institutions involved with undergraduate teaching in the field of mining engineering and mine surveying - and the progression of education models since the establishment of the original School of Mines in Kimberley. He also showed how the legacy of these education models can be transformed into a set of qualifications that will benefit all those who choose to pursue mine surveying as a profession. In his second article, he described the evaluation of accuracy standards of a typically configured sidewall station survey network in a narrow mine tunnel environment. The sidewall system lends itself to reduced risk exposure and greater efficiency coupled with added redundancy normally not found in standard underground networks. In another such study, Thomas Afeni and Frederick Cawood discussed total station survey monitoring and developed a systematic error correction formula to reduce the effect of glass properties, such as thickness and colour, on distance measurements through a shelter window glass in a surface mine environment. They concluded that the formula performed well when tested on two mine sites. This research has significant implications for the design of a shelter to protect total stations from atmospheric conditions and theft at surface mines.

Sibusisiwe Hlela, Serena Coetzee and Antony Cooper carried out qualitative research regarding the availability of geographic information within the Department of Environmental Affairs (DEA) by describing the department's contribution to South African SDI objectives and by assessing the DEA's SDI readiness. They proposed the need for future research as the South African SDI is still in its early stages of development. 
Finally, Peter Schmitz described the production of 3D visualisations for forensic maps that were used in a fraud case. His work highlights the production path followed from identifying the sources of data and the acquisition of the data, to the creation of the various 3D visualisations and the final report.

This special edition represents the efforts of many people. I would like to express my gratitude to the members of the Academic Programme Committee and the external reviewers for their hard work in reviewing submissions. The paper submission and reviewing process was managed using the EasyChair system.

Finally, I want to thank Hamid Ashraf for his tremendous effort in administering the EasyChair process and continuously and patiently communicating with me and the reviewers. His support and the advice given by Clare van Zwieten, is truly appreciated.

Prof. Frederick Cawood (University of the Witwatersrand)

Chair: Academic Programme Committee

Geomatics Indaba 2016

\section{Members of the Academic Programme Committee (Alphabetical order)}

Aslam Parker (Department of Rural Development and Land Reform)

Clare van Zwieten (EE Publishers)

Frederick Cawood (University of the Witwatersrand)

Gregory Breetzke (University of Pretoria)

Julian Smit (University of Cape Town and South African Journal of Geomatics)

Raubie Raubenheimer (Cape Peninsula University of Technology)

Serena Coetzee (University of Pretoria)

\section{External Reviewers (Alphabetical order)}

$\begin{array}{ll}\text { Aslam Parker } & \text { Hamza Naveed Tipu } \\ \text { Charles Merry } & \text { Julian Smit } \\ \text { Chris Munyati } & \text { Huw Thomas } \\ \text { Cornel George } & \text { Onisimo Mutanga } \\ \text { Frederick Cawood } & \text { Peter Schmitz } \\ \text { Elhadi Adam } & \text { Philemon Tsela } \\ \text { Georg Gartner } & \text { Raubie Raubenheimer } \\ \text { Gregory Breetze } & \text { Serena Coetzee } \\ \text { Hamid Ashraf } & \text { Stefania Merlo }\end{array}$

